\title{
Editorial
}

\section{Physician commitment, professionalism and conflict of interest}

\author{
Journal of the Ceylon College of Physicians, 2016, 47, 1-2
}

The Sri Lankan physician has enjoyed a long track record of good standing within the profession and in society at large. Being held to a demi-god status by ever grateful patients and their families, physicians receive accolades from mentors and mentees alike. However, these "privileges" enjoyed by clinicians have, at times, blurred the lines of societal and ethical norms. Nevertheless, the exceeding of boundaries of accepted norms have on many occasions been overlooked. The ethical responsibilities of physicians need to address how our external links related to work have the potential to compromise our professional obligations and status. Chief among such potential for compromise is in the fields of conflicting interests.

The definition of 'conflict of interest' (COI) is a conflict between the professional or personal interests and needs of a health care provider and his or her professional responsibilities toward a patient ${ }^{1}$ e.g. personal financial gain based on the use of one drug rather than another to achieve the same clinical outcome. COI in clinical practice is unacceptable, as it can undercut the health and well-being of our patients, who are our prime responsibility. The enormous trust placed on us by patients as their care givers must not be compromised.

COI, being an important problem that has permeated into clinical medicine, is a worldwide issue that has received due attention by professional groups overseas and locally. An approach to tackling COI has extended to a wide range of other professional fields such as law, journalism, finance and business. Many leading overseas Colleges of Physicians, over the past two decades in particular, have addressed $\mathrm{CO}$ in clinical practice. A position statement of the American College of Physicians (ACP) observed that "physicians meet industry representatives at the office and at professional meetings, collaborate in communitybased research, and develop or invest in health-related industries. Such partnered activities often offer important opportunities to advance medical knowledge and patient care, but they also create an opportunity for the introduction of bias". ${ }^{2}$ Even in instances in which no actual conflict exists, the appearance of such a conflict can undermine the credibility of the clinician and the associated institution. Hence, measures must be taken to eliminate bias and to protect patients by ensuring that the relationship between clinicians and the industry is fully acknowledged by the physician by introducing the potential for $\mathrm{COI}^{3,4}$
The CCP has also recognized that the institution and its members run a risk of compromising professional responsibility through such partnerships and has identified the issue in its long term strategic plan through its subcommittee on Patients, Ethics and the Community (PCEC). There is scope to further improve and maintain transparency in Sri Lanka through deliberation and discussion. We all agree that clinical medicine should be practiced in accordance with the best available evidence, which require regular updates on intensive international scientific discussions that have been achieved at a high cost, where COI has also been declared by all parties involved. Nevertheless, we the local physicians and groups, have to ensure that such evidence is appropriate to our own clinical milieu and patient needs, and also bear in mind the cost effectiveness of such evidence based clinical practice in Sri Lanka. Such ventures often require collaboration between the physician, the industry and our College, by arranging academic meetings which may even require travelling overseas, and in developing guidelines. Given the lack of state funding for College activities in this regard, collaborating with the industry offers a seemingly benign source of funding.

Individual physicians often find themselves overloaded with clinical duties with limited support at work stations. The overstretched physicians then find it difficult to remain up-to-date, due to suboptimal opportunities for conscious continuing professional development (CPD) and to engage in clinical research. The need to engage in private practice is some what justified, due to financial needs to fulfill individual family obligations in parallel with self-funded CPD through payment of international professional dues, journal subscriptions and technological support. The lack of time and space for multi-tasking between clinical service, teaching and research also contribute to an overall chaotic and tiring individual professional life for most of us physicians, who often place our own personal health at stake.

In contrast, the corporate sector to which the pharmaceutical industry and medical device manufacturers belong, have many of the required support that are not available to us physicians from their own establishments. Although these establishments have over decades directly contributed to medical research and helped in the improvement of patient care, they prioritize profit on behalf of their shareholders. In the light of the physicians' long held commitment to 
"service before self" and the adoption of the pledge made on the Hippocratic oath, can a market oriented approach be applied by a professional college, a group of physicians or an individual physician? A responsible group of medical professionals and their institutions need to have patients' interests first, regardless of any financial or personal benefit. Nevertheless, the potential for a COI remains high and makes the IndustryPhysician-College relationship extremely vulnerable. Collaborations must therefore be carefully regulated and in some instances prohibited - to protect patients' well-being, promote scientific integrity and ensure the public trust. ${ }^{3}$

Responsible professional bodies such as our College need to engage in an official COI policy that recognizes these obligations. An effective and responsible policy should clearly specify the relationships and activities that are acceptable; those that are prohibited, and provide clear guidelines to our institution and members on how to remain transparent at all times. The position statement of many overseas colleges alludes to physicians' meeting with industry representatives, collaborating in research, and in developing health-related industry; all of which no doubt contribute to advancement of knowledge and improved patient care. They address physician bias and COI, out of line with the physicians' primary professional obligation. The privileges enjoyed by physicians include the ability to set educational and ethical standards. However, such an authoritative status must ensure the adherence to avoid the permeation of self-interest and selfimprovement that can override professional responsibility. Physician financial relationships with industry must address COI when accepting gifts, company sponsored meals and drug samples, when invited as promotional speakers for the launch and marketing of products and in the prescription of these same products. Other instances that place the physician at risk for $\mathrm{COI}$ include receiving payment for services, in the ownership of health care facilities and in self-referral.

Therefore a professional code of conduct and statements on conflicts of interest in all proceedings of our College would prove to be a good start to generating a wider discussion and collective thought on this subject. Simple recommendations for the College, members and the industry may help establish a basic framework that we all can function within and avoid embarrassing and unwarranted issues arising from clear conflicts of interest in our professional duties.

\section{Chandrika N Wijeyaratne \\ Co Editor \\ JCCP}

\section{References}

1. Definition: 'Conflict of Interest', www.medilexicon.com/ medicaldictionary

2. Coyle SL. Ethics and Human Rights Committee, and American College of Physicians-American Society of Internal Medicine. Physician-industry relations. Part 1. Individual physicians. Annals of Internal Medicine 2002; 136: 396-402.

3. Institute of Medicine (US) Committee on Conflict of Interest in Medical Research, Education, and Practice; Lo B, Field MJ, editors. Conflict of Interest in Medical Research, Education, and Practice. Washington (DC): National Academies Press (US); 2009. http://www.ncbi.nlm.nih.gov/books/NBK22944/

4. Ashley Woodcock, Declaration of Interests, Royal College of Physicians (RCP) policy document, 2011. 